\title{
Learning Structures of CDIO-Based Projects in Contexts of Demola*
}

\author{
Daniel Einarson \\ Kristianstad University, Kristianstad, Sweden \\ Karin Wendin \\ Kristianstad University, Kristianstad, Sweden; \\ SP Technical Research Institute of Sweden, Lund, Sweden \\ Diana Saplacan \\ Kristianstad University, Kristianstad, Sweden
}

\begin{abstract}
Academia plays a main role in knowledge discovery and dissemination of knowledge. Amongst the fundamental reasons behind university education lies preparing students to use and contribute with that knowledge within contexts of industry, as well as society in large. We here see three types of actors, i.e., universities, students, and industry, which by several reasons all are gained by close cooperation already in university education. Quite often though we see a gap between education and possible student recruitment. Here, the value of being employable increases through work-based projects supported by education. Even though we can see willingness according such kind of cooperation from both academia and industry, experiences show that there are barriers towards actually implementing this. That may in turn depend on common lack of knowledge on how to establish university-industry connections, and how to negotiate on student involvement, ownership of work, etc.. Conclusions therefore show a need for an established organization that mediates between academia and industry, and that have well-developed structures for project workflow, project result ownership, etc.. Demola may here have that role as an award-winning platform for industry-driven projects with focus on students. Demola provides a win-win-win relationship between university, students, and industry, and has clear structures for cooperation between those. Experiences have shown that Demola is promising as a mediator, as well as a provider of multi-disciplinary industry close projects, where those may be plugged into educational programs in suitable ways. This contribution will provide an overview of Demola as a platform for industry close student projects. Demola may furthermore be used as a platform for research projects. Experiences will here be covered as a concrete example on a Demola student project. Moreover, learning outcomes in contexts of Conceiving-Designing-Implementing-Operating (CDIO) Syllabus, evaluations, and corresponding CDIO Standards, will be presented.
\end{abstract}

\footnotetext{
* This work is licensed under a Creative Commons Attribution-NonCommercial-NoDerivs 3.0 Unported License.

Acknowledgments: Special thanks to students of the project covered in this contribution. Also, special acknowledgments to contributors of the research project (Vinnova, Formas, SLF, Svensk Dagligvaruhandel and LI). Furthermore, great thanks to the anonymous reviewers of the 11th International CDIO Conference, for valuable comments on the abstract.

Daniel Einarson, Ph.D., senior lecturer, Department of the Computer Science, Kristianstad University.

Karin Wendin, Ph.D., professor, Department of Food and Meal Science, Kristianstad University; SP Technical Research Institute of Sweden.

Diana Saplacan, M.Sc., lecturer, Department of the Computer Science, Kristianstad University.
} 
Keywords: university-industry cooperation, project-based work, work-based learning, research projects, learning outcomes, CDIO standards $1,2,5,6,7$, and 8

\section{Introduction}

Propositions from universities, according work-based learning to improve employability, point out that industry close projects are strongly encouraged. CDIO (Conceiving-Designing-Implementing-Operating real world systems, http://www.cdio.org) does, neither in the standards nor in the syllabus, explicitly mention that experiences should take place in direct cooperation with industry. Certainly, reasons behind this may include difficulties to find sustainable cooperation between academia and industrial partners, and how well industry projects live up to appropriate learning outcomes. Therefore, developing new concepts according industry close cooperation should illuminate on potentials for sustainability and reasonable learning structures. Furthermore, research-based student projects with similar work-based forms as industry close projects, need the same correspondences to learning outcomes as industry close projects do. Hence, concepts developed for industry close projects should be suitable also for research projects.

Demola, ${ }^{1}$ originating from Tampere, Finland, is a collaborative open innovation platform for students, universities, and companies. Its successful award-winning approach ${ }^{2}$ has influenced several other European regions to participate in the Demola network. The concept relies on well-established agreements between universities, students, and companies. Companies act with low risk and may experiment on innovative real-life systems with help from multi-disciplinary student teams. Projects are controlled by contracts between a student group and a company, where satisfactory developments are financially regulated. Here, innovation is in focus, which makes Demola clearly different from more practice-oriented work-based projects. This in turn sheds light on the ownership of the product where this lies on the student group. The corresponding company may then in case of success choose to procure the full rights of the project results.

Demola has recently been introduced in what is called Demola South Sweden, ${ }^{3}$ involving several participants from academia, companies, and other organizations from that region. So far, there have been positive experiences in Demola South Sweden, from the point of views of involved teachers, companies, students, as well as the Demola organization itself. Such results has also emphasized the interest in development of research projects in the context of Demola. During the Autumn Semester 2014, a research project with participants from both academia and industry has partially been studied and developed in the context of Demola. It is here especially interesting to study the value of the students' learning process, as well as the value for the research project as such.

This contribution will present how Demola generally may contribute to CDIO-based learning. Especially, the values of the research project as a student learning process will be presented in terms of the CDIO Syllabus learning outcomes (CDIO Syllabus, n.d.). To generally increase Demola as a learning platform, correspondences to the CDIO standards (CDIO Standards, n.d.) will be presented.

\footnotetext{
${ }^{1}$ Demola, about (http://demola.net/about).

2 Demola, award, selected as the best cross-border and cross-sector innovator in the Baltic Sea Region (http://demola.net/news/demola-selected-best-cross-border-and-cross-sector-innovator-baltic-sea-region) and listed by the Organization for Economic Co-operation and Development (OECD) and the World Bank as a best practice for innovation policy-makers globally (https://www.innovationpolicyplatform.org/document/demola-open-innovation-platform).

${ }_{3}^{3}$ For more information, please visit http://southsweden.demola.net/.
} 


\begin{abstract}
About Demola
The Demola concept constitutes a node between academia and companies (and other organizations) with facilitators, and fully-developed rules, for cooperation between those parts (Einarson \& Lundblad, 2014). Focus is on students and innovative multi-disciplinary projects. Companies have a chance to experiment on ideas, and academia is gained by contacts with industry partners to provide industry close projects to students. Furthermore, students get contacts with possible future employers, and generally improve their values of being employable. That is, Demola provides an ecosystem with several winners.

For developing projects, Demola proposes an agile development style (Agile development, n.d.), where conceive, design, and implementation evolve through iterative collaborative steps. Recurrent meetings take place with company representatives, feedback is provided by university teachers, and Demola facilitators are continuously in the discussion and feedback loop, with supporting seminars and workshops. Students should take at least their third year to be able to apply required amount of disciplinary knowledge. Furthermore, students have recurrent oral presentations, where they pitch their work so far. They should also document their work through project plans and project reports.
\end{abstract}

\title{
On Demola Process
}

A Demola course runs during 15 weeks. Each student is required to put between 12 and 15 hours/week, which makes about 200 hours of work into the project as a whole. The process is divided into three main phases of about five weeks each, where there are held workshops and seminars. The transition from one phase to another is marked by a pitch event, where students present their work and get feedback from project providers, i.e., companies, university supervisors, and others. Below, those phases are described, with the corresponding workshops and seminars, as well as the pitching events held in-between each of the phases.

Phase I is an initiation phase focusing on the idea generation and team building. This phase, as shown in Figure 1, includes several activities, such as an idea generation workshop, or so-called ideation, using brainstorming and innovative methods, such as user stories, storyboard, lo-fi prototyping, and other methods, in order to identify, evaluate, and validate important customer and market needs that shall be taken into account later on in the design.

Value creation workshop has a focus on Needs, Approach, Benefits (per costs), and Competition (or alternatives) (NABC) method. The method was initially developed by Stanford Research Institute International (SRI), and now it is adopted worldwide in various industries due to its effective impact (Carlsson \& Wilmot, 2006).

First pitch, it is only a one minute pitch, and it is done individually by each of the students. The pitch follows NABC structure. The main goal for this first pitch is that students get a first feedback from Demola facilitators on the NABC method.

Phase II (see Figure 2) is focused on the project plan and thereafter most of the focus is on execution of the project. The students will also get feedback on their project plan from their project providers and examiners. However, during this phase, there are held fewer workshops. Companies might have workshops for their teams, or for all of the students. Such examples are workshop on agile methods, with concrete steps on how to get started now from idea to concept or prototype, in an agile way, by using mind mapping tools, personas, and planning, and prioritizing of tasks. During this phase, the students will also work independently in their teams. They will meet their facilitator one to two times a week, as well as their project provider, approximatively each every two weeks. 


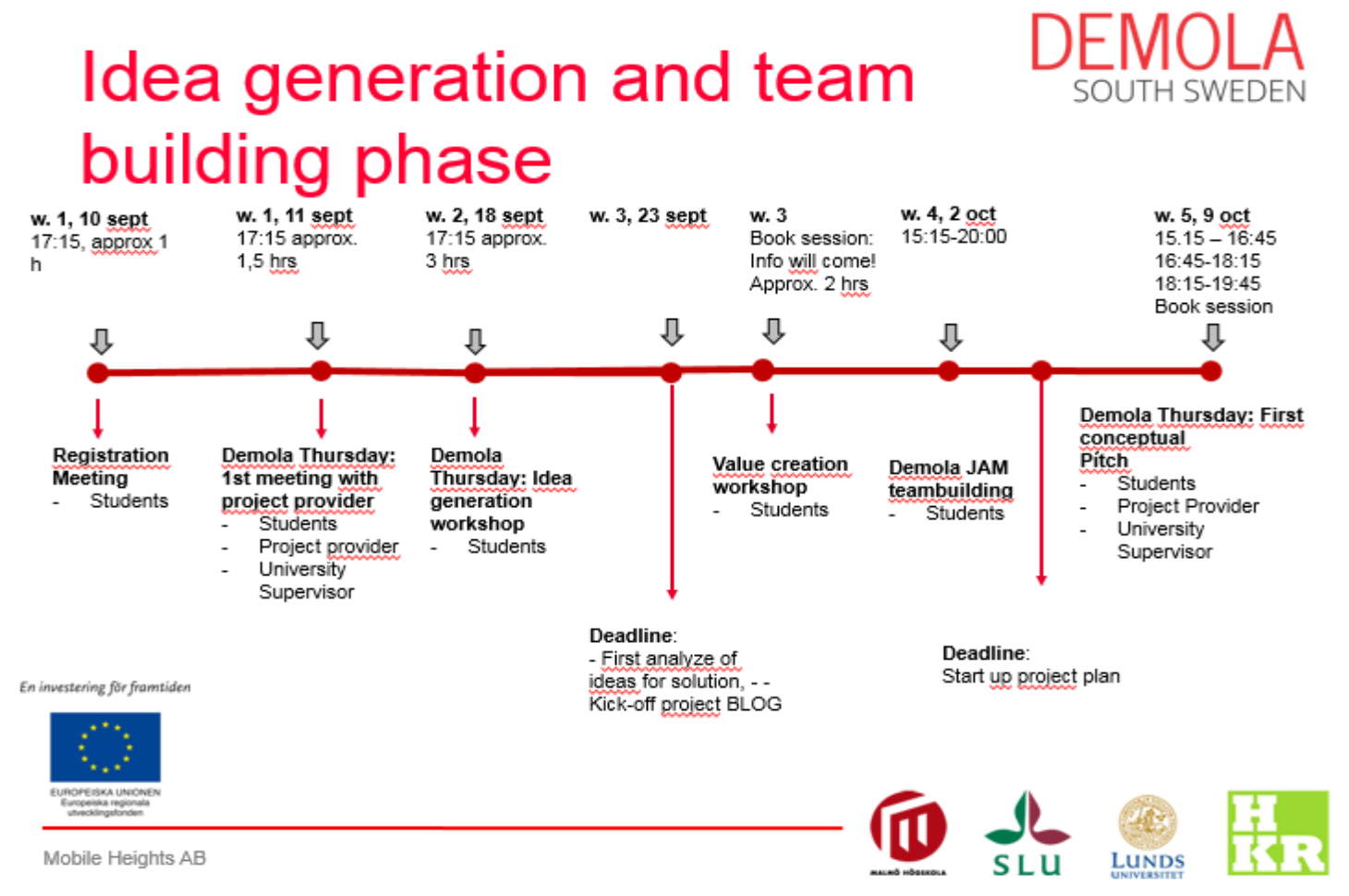

Figure 1. Phase I.

\section{Project plan and start execution}

$$
\text { w. } 6
$$

W. 6
Book session

w. 6,16 oct

w. 7

w. 7,23 oct

w. 8,30 oct

w. 9, 6 nov

$15.15-16: 45$
$16: 45-18: 15$

16:45-18:15
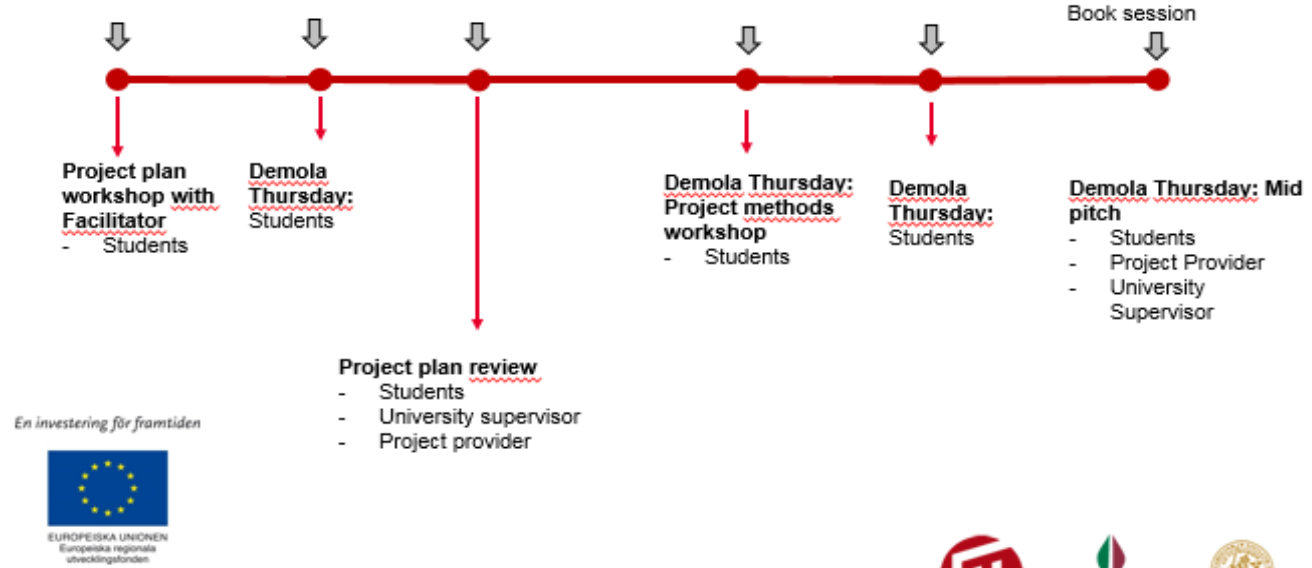

Mobile Heights AB

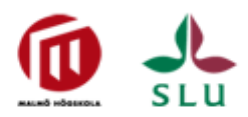

DEMOLA

SLU

LUNDS

Figure 2. Phase II.

Second pitch, also called mid-pitch, is a three minutes long pitch and is done in teams, rather than individually. The students have now the first opportunity to sell the idea to their project providers, as well as to get feedback from them, their examiners, and other students. 
Phase III is focused on finalizing the project and on the project's final report which shall be approved by the university examiners and project providers. This is done by having a meeting, where all parties are present. The students are given opportunity for completion, if the project provider or examiners consider that there are parts that should be written more in-depth.

During this phase, the students are given an extra opportunity to practice their pitch and get feedback before their final pitch. This is arranged by Demola network in collaboration with other external collaborators, such as maker-spaces that hold open events or others (e.g., STPLN Hub, companies at Ideon Science Park, etc.). This is seen by students as very valuable, especially because they get feedback from external potential customers.

Finally, the course is closed by the final pitch event, where the students shall present their finalized concept or prototype to the project providers and examiner. The final pitch is five minutes long. After this pitch, the companies have the right to decide if they wish to license the concept or prototype developed by students, within three months since the day of final pitch.

\section{What Does Innovation Mean at Demola}

Innovation would be defined by Carlsson and Wilmot (2006) at SRI as "the process of creating and delivering new customer value in the marketplace." Innovation at Demola is defined not only by NABC SRI method, but also by the participatory design processes where co-creative processes in cross-disciplinary teams are encouraged. Demola advocates for the fact that creativity comes from cross-disciplinary combined knowledge. Therefore, innovation is in this way facilitated, as the user-experience is enhanced of the complementary aspects that are researched by the cross-disciplinary team. This is also referred in other researches and contexts, as innovation driven by meaning. More specific, this type of innovation focuses on enhancing or creating an experience, rather than improving performance of existing contexts.

This paper will exemplify this type of innovation through a research project, where new solutions for home food delivery for the elderly is approached, instead of trying to improve old solutions.

\section{On Demola Contributions to CDIO}

Demola approaches industry close projects in ways that are suitable both for academia and industry. In Einarson and Lundblad (2014), it was shown how Demola projects meet learning outcomes in the perspective of CDIO Syllabus. From the perspective of learning objectives of Demola project courses and CDIO Syllabus Level 2, the following correspondences were shown:

1. Achieve experience in project work and project methods and management (Corresponding to 4.2, 4.3, 4.4, and 4.5);

2. Achieve oral presentation skills (Corresponding to 3.2 and 3.3);

3. Achieve documentation skills (Corresponding to 3.2 and 3.3);

4. Achieve experience in developing an idea from scratch to a demo or a prototype (Corresponding to 2.1, $2.2,2.3,4.3,4.4$, and 4.5$)$;

5. Achieve team working skills (Corresponding to 3.1).

Demola's contribution to CDIO Standards was presented in Einarson and Lundblad (2014) as follows:

Standard 1: Demola projects support the view on CDIO as a whole, and contribute well to CDIO-based educational program, based on the same engineering spirit.

Standard 2: Demola course learning objectives contribute well to those of a CDIO-based engineering program. Stakeholder from companies are directly involved. 
Standard 5: A Demola project corresponds here to a design-build example on an advanced level.

Standard 6: Demola contributes with an arena for creativity and innovation. Students work together there and also meet Demola facilitators and company representatives.

Standard 7: Demola contributes clearly to integrated learning experiences.

Standard 8: Similarly, Demola contributes to active learning, in being one piece of a full CDIO picture.

A conclusion here is that Demola generally contributes well to CDIO-based educational programs. In the sequel, more will be provided on this, and at more concrete levels.

\section{About Research Project}

In Sweden, and in most parts of the world, the proportion of elderly is increasing. The number of the elderly will shortly exceed the number of younger people. Between 2010 and 2030, the number of Europeans aged over 65 will rise by nearly $40 \%$. According to the United Nations, the increase in life expectancy is mainly due to improvements in nutrition and hygiene. The growing number of older people poses major challenges, but also opportunities for society, business, and entrepreneurship.

Health issues, primarily food, pharmaceutical and hygiene, and quality of life are in focus and strongly related to autonomy. It should be possible to live an active and independent life, and possible to make independent choices, regardless of age, disease, and disability. This adds to quality of life!

The project aims to add to quality of life through possibilities to choose what to eat and where and when to have a meal! The growing number of elderly poses both challenges and opportunities. It should be possible to live an independent life and make own choices, regardless of age, disease, and disability. In the project, target groups along with their needs and desires are identified. From this, foods and meals are designed along with packaging. Chains of distribution as well as waste management are developed. A demonstration of the chain from consumer preferences to waste will finalize the project.

The purpose of the Demola project is to create a system that will help resolve the uncertain food situation currently being experienced by the elderly people. Today, an existing number of food supply systems are not managed by one entity. With the student proposed solution, different stakeholders can interact with each other. The objective is to create a centrally managed back-end system that will coordinate the supply, transportation, and delivery of food to the stay-at-home elderly (see Figure 3). Main focus areas are the view and interaction management of the system provider. The aim is to create a reliable food supply system that ensures the customer needs are met including real time system operation, quick response, and security.

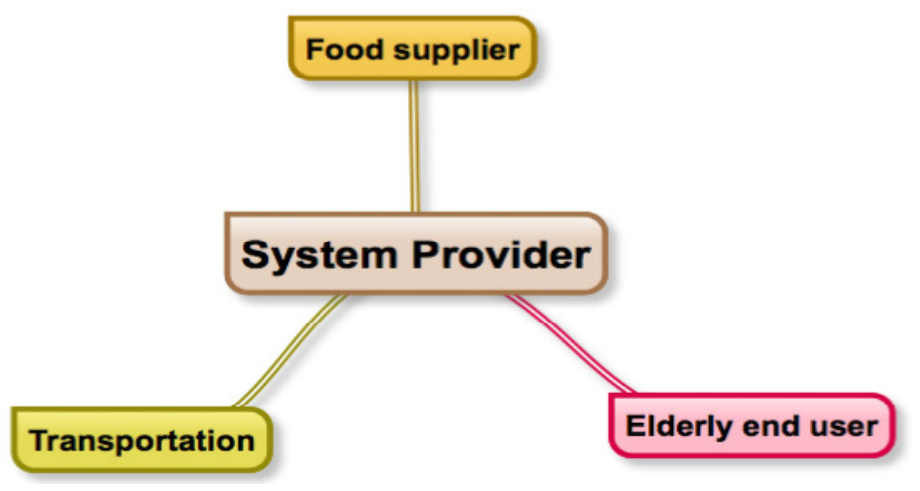

Figure 3. Project system main entities. 


\section{The Research Project as a Demola Project}

Student groups normally should be multi-disciplinary to meet different aspects of a project. Since Demola South Sweden involves several universities, students also often have different home universities. Demola acknowledges English as the prime language, to also allow for international students to take the course. This multi-university, multi-disciplinary, and multi-cultural environment allows for several interesting possibilities and experiences, as well as problems in coordination and negotiations.

Originally, the project group involved six students, and was structured to suit the aim of the project as far as possible. Subjects of studies and interest were as follows, with students named S1 to S6:

S1: Media and design (previously computer science);

S2: Economics, and economy and management;

S3: Computer science and software engineering;

S4: Computer science and software engineering;

S5: International migration and ethnic relations, and public health;

S6: Logistics, with special interest in packaging technologies.

Unfortunately, student S6 left the group and the Demola project course quite soon, and student S5, after a couple of weeks, leaving a group of students S1-S4. Furthermore, students S3 and S4 are taking a course in Software Engineering (SE2), at Kristianstad University, where the Demola project is a part of that course. Structures behind handling this are described in Einarson and Lundblad (2014).

A student group has one dedicated Demola facilitator, at least one university supervisor/examiner, and one project provider (typically a representative from industry). All three co-authors of this contributions have more or less interest in the research project as such. Overlapping roles are here seen as beneficial, as well as it may introduce risks of conflicts between those roles. Co-authors (C1, C2, and C3) here act as follows:

$\mathrm{C} 1$ acts as a university representative from Kristianstad University, i.e., a supervisor and examiner, both for students from Kristianstad University, and other universities. He also has the role of being project provider for the project group. This means that he was the main contact person for the students according to project requirements and product outcomes. Examination of the students of the project is here done with help from co-teachers from Kristianstad University.

$\mathrm{C} 2$ acts as the research project leader, and stands for the contract between company (here the research project) and students.

C3 acts as the student project group's dedicated Demola facilitator. She is also a lecturer in the course SE2. There are no formal dependencies between her work as a lecturer and her work as a Demola facilitator. The latter is more of an external assignment as a part of Kristianstad University's involvement in Demola South Sweden.

From the experiences of the project provider, and from the group's final report, it could be seen that the group's understanding of the problem changed overtime. A first focus was on the elderly and their needs, and a solution target on an App that could help meet their needs. Communication between the group and the project provider showed that there already was developed a prototypical App for such purposes, switching focus to a back-end section of a supply chain system, where that App should be plugged into that system. Especially, a so-called system provider was pointed out, to link all the food supply chain entities as illustrated in Figure 3. 
A prototype of the system was designed and implemented to be able to have more actors plugged into it. The system manifests the idea that all relevant parties can work together and communicate through the system to provide better service to the different users.

The project provider $(\mathrm{C} 1)$ and the project leader $(\mathrm{C} 2)$ were both satisfied with the project result, and decided that it was reasonable to buy the license to the project according to the contract. Furthermore, students S3 and S4 will proceed with developing the project in a context of their candidate final thesis.

\section{Learning Outcomes Reflected by the Project}

From the group's report and supervisor's observations during the process, it can be concluded that the project has several correspondences to CDIO Syllabus learning outcomes. This is especially clear concerning Section 3 (Interpersonal Skills) of the CDIO Syllabus, from several subsections of Level 2 and Level 3. Examples here include "Forming Effective Teams" (3.1.1), "Team Operation" (3.1.2), "Team Growth and Evolution" (3.1.3), and "Technical and Multidisciplinary Teaming" (3.1.5) (CDIO Syllabus, n.d.). Team members are chosen by the Demola facilitators, still, it is up to the team to find suitable member roles and forms for the work. In several cases (as in this), change in team structure will occur due to students leaving the project. From the report, "This affects the project because the project team had to reshuffle roles and responsibilities every time a member left."

An obvious effect of the project is that it is put within an external, societal environmental context (4.1), where the enterprise and business context (4.2) should be outlined. The report outlines the context of competitors and points out the research project's strengths within that context. Besides from this, especially "Conceiving and Engineering Systems" (4.3), "Designing" (4.4), and "Implementing" (4.5) have been crucial for the project development. For instance, "Understanding Needs and Setting Goals" (4.3.1) and "Defining Function, Concept and Architecture" (4.3.2) have been critical due to misinterpretations of the project provider's requirements, and solved through several meetings for discussions and the team updating the project provider of solution development.

Several personal and professional skills and attributes (Section 2 of the CDIO Syllabus) have been mirrored and practiced on by the project. Those include "Problem Identification and Formulation" (2.1.1 as performed both at a personal level and that of the project group, as 4.3.1), "Modeling" (2.1.2), "Thinking Holistically" (2.3.1, here especially "A system, its function and behavior, and its elements" and "The societal, enterprise and technical context of the system"), and "Initiative and Willingness to Make Decisions in the Face of Uncertainty" (2.4). Interesting is here also to see how the group reflects over ethical issues, a crucial matter where personal information is critical. At the prototypical level of the project, those concerns have neither been captured in the design nor the system implementation. Rather it has been mentioned as important focus aspects. From the report:

Information privacy of the different parties involved in the solution system. Health and safety issues of the consumer including: how the food is prepared, packaged and transported from the producer to the consumer, and the different health issues experienced by the elderly (including fading abilities and nutrition).

\section{Project Survey and Evaluation}

While the discussions above motivates learning outcomes from perspectives of teachers' observation and definition of course structures, a student survey and evaluation will motivate learning outcomes from perspectives of student experiences. A survey has been performed involving the four students of the project 
team, three of them fulfilled the survey. The students were asked to comment on how working with the project met several learning outcomes. It is out of the scope of this contribution to provide the full survey set, however, outlined below.

Defining function, concept, and architecture:

This was made easier with tools, such as the agile methodology and consistent communication with the project provider. The shift in the direction of the solution caused a few setbacks, which was a lesson in itself. I found that to be positive-Our concept started out as a broad topic. We had to dig deeper to get to the real problem and then work from there-I have learned the whole software development cycle and product cycle. How the function is defined, how the concept is formed and then architecture is designed in the process.

Understanding needs and setting goals:

The language barrier hindered the understanding of the two to some extent, but it was made much easier with research and investigation - Our group set up weekly goals for the most part. It has been good having goals so that we keep moving forward - It is important to communicate with customers and analyze the business requirements and product definition.

\section{Conclusion}

This contribution has pointed out Demola, as an appropriate concept for industry close student projects, still meeting demands from academia on, e.g., leaning outcomes. This has been proven through the use of $\mathrm{CDIO}$ as an international educational reference system. The structure of Demola, its process, and its correspondences to CDIO have been outlined in contexts of CDIO Syllabus and Standards. An example has been provided through a research-based project involving several partners from industry. The reason to this is two-folded. On one hand, it concretizes Demola within the CDIO context, and on the other hand, it proves that research and development projects may benefit from Demola.

\section{References}

Agile development. (n.d.). In Wikipedia, the free encyclopedia. Retrieved from http://en.wikipedia.org/wiki/Agile_development Carlsson, R. C., \& Wilmot, W. W. (2006). Innovation-The five disciplines for creating what customers want. New York, N.Y.: Crown Business.

Conceiving-Designing-Implementing-Operating (CDIO) Standards. (n.d.). CDIO Standards 2.0. Retrieved from http://www.cdio.org/implementing-cdio/standards/12-cdio- standards

CDIO Syllabus. (n.d.). CDIO Syllabus 1.0. Retrieved from http://www.cdio.org/node/5993

Crawley, F. E. (2001, June 20-23). The CDIO Syllabus-A statement of goals for undergraduate engineering education. Proceedings of The 7th International CDIO Conference, Technical University of Denmark, Copenhagen.

Einarson, D., \& Lundblad, H. (2014, June 16-19). Demola-The upcoming win-win relationship between university and industry. Proceedings of The 10th International CDIO Conference, Universitat Politècnica de Catalunya, Barcelona, Spain.

Öberg, Å. (2012). Innovation driven by meaning (Doctoral dissertation, Mälardalen University). 